Correspondence

Edet E. Udo

EDET@hsc.edu.kw

Received 25 November 2010 Accepted 28 January 2011

\section{Detection and characterization of an ST97-SCCmec-V community-associated meticillin-resistant Staphylococcus aureus clone in a neonatal intensive care unit and special care baby unit}

\author{
Edet E. Udo, ${ }^{1}$ Nasser Yehia A. Aly, ${ }^{2,3}$ Eiman Sarkhoo, ${ }^{1}$ Rima Al-Sawan ${ }^{4}$ \\ and Al-Sayed M. Al-Asar ${ }^{5}$
}

\author{
${ }^{1}$ Department of Microbiology, Faculty of Medicine, Health Science Center, Kuwait University, Kuwait \\ ${ }^{2}$ Department of Tropical Medicine and Hygiene, Faculty of Medicine, University of Alexandria, Egypt \\ ${ }^{3}$ Department of Infection Control, Farwaniya Hospital, Ministry of Health, Kuwait \\ ${ }^{4}$ Department of Paediatrics, Farwaniya Hospital, Ministry of Health, Kuwait \\ ${ }^{5}$ Department of Laboratories, Farwaniya Hospital, Ministry of Health, Kuwait
}

\begin{abstract}
A total of 29 meticillin-resistant Staphylococcus aureus (MRSA) isolates were obtained from 15 neonates and three healthcare workers (HCWs) in a neonatal intensive care unit (NICU) and special care baby unit (SCBU) and four patients in a medical ward of a Kuwait hospital between 10 and 30 April 2007. The isolates were characterized using antibiogram results, coagulase gene RFLP (coa-RFLP), PFGE, staphylococcal cassette chromosome mec (SCCmec) typing and multilocus sequence typing (MLST). All isolates were assessed for the carriage of PantonValentine leukocidin (PVL) and arginine catabolic mobile element (ACME) genes. The isolates belonged to three SCCmec types, six coa-RFLP types, six pulsotypes and six sequence types. One isolate was positive for PVL. None were positive for ACME. All MRSA isolates from the 15 neonates were phenotypically and genetically different from the MRSA isolates obtained from HCWs and those from patients in other wards. They were resistant to gentamicin, kanamycin and fusidic acid, had identical coa-RFLP and PFGE patterns, carried the type V SCCmec element and belonged to MLST sequence type ST97. The results showed the transmission of a rare clone of community-associated MRSA belonging to ST97 with the SCCmec-V genotype among neonates in a NICU and SCBU.
\end{abstract}

\section{INTRODUCTION}

Community-associated meticillin-resistant Staphylococcus aureus (CA-MRSA) emerged in the 1990s among patients in remote communities with no access to healthcare facilities (Udo et al., 1993; Groom et al., 2001) and without the established risk factors for MRSA infection or colonization such as prior antibiotic use, prior hospitalization and old age (Naimi et al., 2003). Since then, CA-MRSA has become a global public health problem. CA-MRSA has been isolated from different patient populations in recent years including

Abbreviations: ACME, arginine catabolic mobile element; CA-MRSA, community-associated MRSA; coa-RFLP, coagulase gene RFLP; HCW, healthcare worker; MLST, multilocus sequence typing; MRSA, meticillinresistant Staphylococcus aureus; NICU, neonatal intensive care unit; PVL, Panton-Valentine leukocidin; SCBU, special care baby unit; SCCmec, staphylococcal cassette chromosome mec. pregnant women and neonates (Chen et al., 2006; Carey et al., 2010; Gould et al., 2009). CA-MRSA is increasing among children in the USA and elsewhere (Mishaan et al., 2005; Song et al., 2010) with increasing reports of outbreaks of infections in neonatal intensive care units (NICUs) (Mishaan et al., 2005; Gould et al., 2009). Outbreaks of CAMRSA infections among neonates can be devastating because of prematurity of organ systems, low birth weight and use of invasive devices with significant morbidity and financial burden although not independently associated with increased mortality (Song et al., 2010).

MRSA was not a problem in the NICU and special care baby unit (SCBU) of Farwaniya Hospital in Kuwait in the 5 years prior to 2007 as revealed by a computerized laboratory data search and infection control registry records. However, between 10 and 30 April 2007, MRSA was isolated from 15 neonates in the NICU and SCBU of 
this hospital. This paper describes the molecular characterization of these MRSA isolates.

\section{METHODS}

Setting. Farwaniya Hospital is a 920-bed general hospital that serves a population of approximately 1000000 . It has Obstetrics and Gynaecology departments that handle $\sim 7000$ deliveries annually. It has a NICU with 19 beds: 8 level III NICU beds in a single large space, 7 intermediate intensive beds in a separate room, 3 single-bed isolation rooms and a single-bed special procedures room. It is separated from the SCBU by a corridor. The standard nurse/bed ratio in the NICU is $2.5: 1$ and in the SCBU is $1: 1$.

S. aureus isolates. Between 10 and 30 April 2007, 15 MRSApositive neonates were identified in the NICU and SCBU. The colonization of two babies was first noticed on 10/4/2007 and 13/4/ 2007 in the NICU followed by infection in two babies (conjunctivitis, bacteraemia) on 16/4/2007 and 17/4/2007. The detection of MRSA from babies on 13/4/2007 warranted microbiological screening of all neonates, nurses, physicians and support staff in the units. Environmental surfaces including incubators, incubator windows, filters, incubator water, humidifiers, IV stands, infusion pumps, X-ray cassettes, ultrasound probes, nursing counter area, patients' files and computer keyboards were also sampled. This resulted in the detection of MRSA from 11 babies and 3 healthcare workers (HCWs; a neonatologist, staff nurse and cleaner). The medical records of all neonates were reviewed to establish history, treatment and outcomes. All isolates were identified using standard bacteriological techniques, which included Gram stain, catalase test, tube coagulase test and DNase test. Pure cultures of the isolates were preserved in $40 \%(\mathrm{v} / \mathrm{v})$ glycerol in brain heart infusion broth at $-20{ }^{\circ} \mathrm{C}$.

Antibiotic susceptibility testing. Testing of susceptibility to oxacillin, benzylpenicillin, cefoxitin, kanamycin, gentamicin, erythromycin, clindamycin, chloramphenicol, tetracycline, trimethoprim, fusidic acid, rifampicin, ciprofloxacin and linezolid was determined by the disc diffusion method following the Clinical and Laboratory Standards Institute guidelines (CLSI, 2007) with S. aureus strain ATCC 25923 as quality control strain. Fusidic acid susceptibility was interpreted according to the British Society for Antimicrobial Chemotherapy guidelines (BSAC, 2005). The MICs of oxacillin, fusidic acid, vancomycin and teicoplanin were determined with Etest strips. Meticillin resistance was confirmed by detecting PBP2a in culture supernatants using a rapid latex agglutination kit (DenkaSeiken) according to the manufacturer's instructions.

Molecular typing of isolates. A combination of coagulase gene typing (Goh et al., 1992) and PFGE (Udo et al., 1999) was used to establish the relatedness of strains. Multiplex PCR was employed to assign SCCmec types I-V as described by Zhang et al. (2005).

Multilocus sequence typing (MLST) was performed by following previously published protocols (Enright et al., 2000).

The lukS-PV and $l u k F-P V$ genes, which encode Panton-Valentine leukocidin (PVL), were amplified as described previously (Lina et al., 1999). The presence of genes for the arginine catabolic mobile element (ACME) $(\operatorname{arcA})$ was investigated by PCR using the primers and protocol described by Ellington et al. (2008).

\section{RESULTS AND DISCUSSION}

In total, 29 MRSA isolates obtained from 15 neonates (21 isolates), three HCWs (three isolates) and four inpatients (five isolates) residing in other wards during the study period were subjected to phenotypic and genotypic typing to establish their clonal relatedness.

All 29 isolates were positive for PBP2a, and were resistant to penicillin G, oxacillin (MIC $48->256 \mathrm{mg} \mathrm{l}^{-1}$ ) and the antibacterial agents shown in Table 1. All isolates were susceptible to vancomycin and teicoplanin (MIC $\leqslant 2 \mathrm{mg}$ $1^{-1}$ ), linezolid and rifampicin. All MRSA isolates from colonized or infected babies were resistant to gentamicin, kanamycin and fusidic acid (MIC $8 \mathrm{mg} \mathrm{l}^{-1}$ ), which was different to the resistance profiles of isolates obtained from HCWs and the patients in other wards.

SCCmec typing revealed that the MRSA isolates from the 15 babies contained the SCCmec type V genetic element, which is a characteristic feature of CA-MRSA. The three MRSA isolates from HCWs contained a type IVa SCCmec element while isolates from patients in other wards carried type IV, IVa and III genetic elements.

Coagulase gene typing and PFGE classified the 29 isolates into six separate groups. As shown in Table 1, all MRSA isolates from the babies had the same coa-RFLP and PFGE patterns. Isolates from HCWs showed two patterns while the five MRSA isolates from other inpatients defined three coa-RFLP and PFGE patterns.

MLST was performed on eight isolates consisting of three isolates representing PFGE pattern A (isolates were from blood, nose and catheter tip) and one isolate representing each of the remaining five PFGE patterns. The results showed that the representatives of MRSA from the babies belonged to sequence type 97 (ST97) and were different from MRSA from HCWs and MRSA isolated from other patients.

None of the MRSA isolates from the babies were positive for PVL genes. Only one MRSA isolate, obtained from one of the patients in a different ward, was positive for PVL genes (Table 1). None of the isolates were positive for genes encoding the ACME.

These results indicated a nosocomial transmission of a PVL-negative, ST97-MRSA-SCCmec-V clone among 15 neonates in a NICU and SCBU in a Kuwaiti hospital. Although the number of reports associating CA-MRSA carrying the SCCmec type IV or V genetic element with infections in NICUs has increased worldwide (Mishaan et al., 2005; Song et al., 2010; Gould et al., 2009), to our knowledge, this is the first report associating ST97-MRSA with nosocomial transmission in a neonatal unit. It is also the first report, to our knowledge, of CA-MRSA with the SCCmec type V genetic element in a Kuwait hospital. CAMRSA isolates reported previously in Kuwait hospitals all carried the SCCmec IV genetic element (Udo et al., 2008).

Prior to this report, ST97-MRSA was reported sporadically in human infections. A few isolates of ST97-CA-MRSA have been reported in the USA (Chung et al., 2004), UK (Ellington et al., 2008), Sweden (Fang et al., 2008), Brazil 
Table 1. Characteristics of MRSA isolates

\begin{tabular}{|c|c|c|c|c|c|c|c|c|}
\hline Isolate & Site $^{*}$ & Resistance pattern $\dagger$ & $\begin{array}{c}\text { MIC (mg } \\
\left.1^{-1}\right)\end{array}$ & coa-RFLP & PFGE & SCCmec & PVL & ST \\
\hline \multicolumn{9}{|c|}{ Neonates } \\
\hline N1 & UVC tip & $\mathrm{Gm}, \mathrm{Km}, \mathrm{Fa}$ & 48 & 104 & A & $\mathrm{V}$ & - & 97 \\
\hline N1 & ETT tip & $\mathrm{Gm}, \mathrm{Km}, \mathrm{Fa}$ & 48 & 104 & A & $\mathrm{V}$ & - & \\
\hline N2 & UAC tip & $\mathrm{Gm}, \mathrm{Km}, \mathrm{Fa}$ & 48 & 104 & A & $\mathrm{V}$ & - & \\
\hline N2 & UVC tip & $\mathrm{Gm}, \mathrm{Km}, \mathrm{Fa}$ & 48 & 104 & A & $\mathrm{V}$ & - & \\
\hline N3 & Eye discharge & $\mathrm{Gm}, \mathrm{Km}, \mathrm{Fa}$ & 48 & 104 & A & $\mathrm{V}$ & - & \\
\hline N4 & Blood & $\mathrm{Gm}, \mathrm{Km}, \mathrm{Fa}$ & 48 & 104 & A & $\mathrm{V}$ & - & \\
\hline N4 & Blood & $\mathrm{Gm}, \mathrm{Km} \mathrm{Fa}$ & 48 & 104 & A & $\mathrm{V}$ & - & 97 \\
\hline N5 & Nose & $\mathrm{Gm}, \mathrm{Km}, \mathrm{Fa}$ & 48 & 104 & A & $\mathrm{V}$ & - & \\
\hline N6 & Umbilicus & $\mathrm{Gm}, \mathrm{Km}, \mathrm{Fa}$ & 48 & 104 & A & $\mathrm{V}$ & - & \\
\hline N7 & Nose & $\mathrm{Gm}, \mathrm{Km}, \mathrm{Fa}$ & 48 & 104 & A & $\mathrm{V}$ & - & \\
\hline N7 & Umbilicus & $\mathrm{Gm}, \mathrm{Km}, \mathrm{Fa}$ & 48 & 104 & A & $\mathrm{V}$ & - & \\
\hline N8 & Nose & $\mathrm{Gm}, \mathrm{Km}, \mathrm{Fa}$ & 48 & 104 & A & $\mathrm{V}$ & - & \\
\hline N9 & Axilla & $\mathrm{Gm}, \mathrm{Km}, \mathrm{Fa}$ & 48 & 104 & A & V & - & \\
\hline N10 & Groin & $\mathrm{Gm}, \mathrm{Km}, \mathrm{Fa}$ & 48 & 104 & $\mathrm{~A}$ & $\mathrm{~V}$ & - & \\
\hline N11 & Nose & $\mathrm{Gm}, \mathrm{Km}, \mathrm{Fa}$ & 48 & 104 & A & V & - & \\
\hline N11 & Pustule & $\mathrm{Gm}, \mathrm{Km}, \mathrm{Fa}$ & 48 & 104 & A & $\mathrm{V}$ & - & \\
\hline N12 & Groin & $\mathrm{Gm}, \mathrm{Km}, \mathrm{Fa}$ & 48 & 104 & A & $\mathrm{V}$ & - & \\
\hline N13 & Nose & $\mathrm{Gm}, \mathrm{Km}, \mathrm{Fa}$ & 48 & 104 & A & $\mathrm{V}$ & - & 97 \\
\hline N13 & Umbilicus & $\mathrm{Gm}, \mathrm{Km}, \mathrm{Fa}$ & 48 & 104 & A & $\mathrm{V}$ & - & \\
\hline N14 & Umbilicus & $\mathrm{Gm}, \mathrm{Km}, \mathrm{Fa}$ & 48 & 104 & A & $\mathrm{V}$ & - & \\
\hline N15 & Umbilicus & $\mathrm{Gm}, \mathrm{Km}, \mathrm{Fa}$ & 48 & 104 & A & $\mathrm{V}$ & - & \\
\hline \multicolumn{9}{|l|}{ HCWs $\ddagger$} \\
\hline SN1 & Nose & Cip & 64 & 20 & B & IVa & - & 22 \\
\hline MD1 & Nose & - & 64 & 16 & $\mathrm{C}$ & IVa & - & 1 \\
\hline CL & Nose & - & 64 & 16 & $\mathrm{C}$ & IVa & - & 1 \\
\hline \multicolumn{9}{|c|}{$\begin{array}{l}\text { Patients in } \\
\text { other wards }\end{array}$} \\
\hline Pt 1 & Nose & Km, Sm, Em, Clin, Tet & $>256$ & 36 & $\mathrm{D}$ & IVa & - & 5 \\
\hline Pt 2 & Wound & $\mathrm{Km}, \mathrm{Sm}$, Tet, Fa & 48 & 768 & $\mathrm{E}$ & IV & + & 80 \\
\hline Pt 3 & Blood & Gm, Km, Sm, Em, Clin, Tet, Fa, Cip & $>256$ & 68 & $\mathrm{~F}$ & III & - & 239 \\
\hline Pt 3 & Nose & Gm, Km, Sm, Em, Clin, Tet, Fa, Cip & $>256$ & 68 & $\mathrm{~F}$ & III & - & 239 \\
\hline Pt 4 & Groin & $\mathrm{Gm}, \mathrm{Km}, \mathrm{Sm}$, Em, Clin, Cm, Tet, Fa, Cip & $>256$ & 68 & $\mathrm{~F}$ & III & - & 239 \\
\hline
\end{tabular}

${ }^{\star}$ ETT, Endotracheal tube; UAC, umbilical arterial catheter; UVC, umbilical venous catheter.

$†$ †ip, ciprofloxacin; Clin, clindamycin; Cm, chloramphenicol; Em, erythromycin; Fa, fusidic acid; Gm, gentamicin; Km, kanamycin; Sm, streptomycin; Tet, tetracycline.

$\ddagger \mathrm{SN}$, Staff nurse; MD, clinician; CL, cleaner.

(Schuenck et al., 2009) and, recently, Lebanon (Tokajian et al., 2010). These ST97-CA-MRSA isolates differed phenotypically and genetically from our isolates. Phenotypically, whereas the isolates in this study were resistant to gentamicin, kanamycin and fusidic acid, the USA isolates were resistant to clindamycin and tetracycline while isolates from the UK were resistant to trimethoprim and ciprofloxacin. The isolate from Brazil was resistant to rifampicin. No resistance was reported for the isolate from Lebanon. Genetically, while the ST97 isolates obtained in the USA, Brazil and Sweden contained the type IV SCCmec element, the isolates obtained in this study, the UK and Lebanon carried the type V SCCmec element. However, all ST97 isolates reported so far have lacked genes for PVL. The only PVL-gene-positive isolate in this study was obtained from a patient in a different ward and was an ST80 clone which has been reported previously in Kuwait hospitals (Udo et al., 2008; Udo \& Sarkhoo, 2010). Whereas the ST97MRSA-SCCmec-V isolates reported in the UK contained the ACME genes (Ellington et al., 2008), those reported in this study were negative.

The source of the ST97 isolates could not be identified. No ST97 isolate was obtained from patients in other areas of the hospital before or after this episode. Although HCWs have contributed to the nosocomial transmission of MRSA elsewhere (Ben-David et al., 2008; Eveillard et al., 2004), the results of this study could not associate the HCWs screened directly with the current outbreak. MRSA carried by the HCWs was unrelated to the ST97 isolates. 
Furthermore, our results could not associate the environment with the transmission of the outbreak strain. We could not rule out maternal transmission since none of the mothers were screened for MRSA carriage. Transmission of MRSA from parents to their infants in the NICU has been reported previously (Al-Tawfiq, 2006).

Interestingly, ST97-MRSA has also been isolated from cows, where it caused bovine mastitis (Smyth et al., 2009; Sung et al., 2008), suggesting that it may be a livestockassociated MRSA clone.

In conclusion, our results suggest a nosocomial transmission of a gentamicin-resistant, PVL-negative ST97 CAMRSA clone with a SCCmec type V genetic element among 15 babies in a NICU and SBCU. However, rapid intervention with adherence to hand hygiene, proper contact precautions, repeated surveillance cultures, successful decolonization of babies and direct observations of infection control practices were crucial factors for rapid containment of the outbreak.

\section{ACKNOWLEDGEMENTS}

The study was supported in part by Kuwait University Research Grant No. YM 05/06.

\section{REFERENCES}

Al-Tawfiq, J. A. (2006). Father-to-infant transmission of communityacquired methicillin-resistant Staphylococcus aureus in a neonatal intensive care unit. Infect Control Hosp Epidemiol 27, 636637.

Ben-David, D., Mermel, L. A. \& Parenteau, S. (2008). Methicillinresistant Staphylococcus aureus transmission: the possible importance of unrecognized health care worker carriage. Am J Infect Control 36, 93-97.

BSAC (2005). BSAC Disc Diffusion Method for Antimicrobial Susceptibility Testing. British Society for Antimicrobial Chemotherapy. http:// www.Bsac.org.uk/Resources/BSAC/version_4_january_2005_final_ NH_April_2.pdf

Carey, A. J., Della-Latta, P., Huard, R., Wu, F., Graham, P. L., III, Carp, D. \& Saiman, L. (2010). Changes in the molecular epidemiological characteristics of methicillin-resistant Staphylococcus aureus in a neonatal intensive care unit. Infect Control Hosp Epidemiol 31, 613619.

Chen, K. T., Huard, R. C., Della-Latta, P. \& Saiman, L. (2006). Prevalence of methicillin-sensitive and methicillin-resistant Staphylococcus aureus in pregnant women. Obstet Gynecol 108, 482-487.

Chung, M., Dickinson, G., De Lencastre, H. \& Tomasz, A. (2004). International clones of methicillin-resistant Staphylococcus aureus in two hospitals in Miami, Florida. J Clin Microbiol 42, 542547.

CLSI (2007). Performance Standards for Antimicrobial Disk Susceptibility Tests; Approved Standard, 9th edn. M2-A9. Wayne, PA: Clinical and Laboratory Standards Institute.

Ellington, M. J., Yearwood, L., Ganner, M., East, C. \& Kearns, A. M. (2008). Distribution of the ACME-arcA gene among methicillinresistant Staphylococcus aureus from England and Wales. J Antimicrob Chemother 61, 73-77.
Enright, M. C., Day, N. P. J., Davies, C. E., Peacock, S. J. \& Spratt, B. G. (2000). Multilocus sequence typing for characterization of methicillin-resistant and methicillin-susceptible clones of Staphylococcus aureus. J Clin Microbiol 38, 1008-1015.

Eveillard, M., Martin, Y., Hidri, N., Boussougant, Y. \& Joly-Guillou, M. L. (2004). Carriage of methicillin-resistant Staphylococcus aureus among hospital employees: prevalence, duration, and transmission to households. Infect Control Hosp Epidemiol 25, 114120.

Fang, H., Hedin, G., Li, G. \& Nord, C. E. (2008). Genetic diversity of community-associated methicillin-resistant Staphylococcus aureus in southern Stockholm, 2000-2005. Clin Microbiol Infect 14, 370376.

Goh, S. H., Byrne, S. K., Zhang, J. L. \& Chow, A. W. (1992). Molecular typing of Staphylococcus aureus on the basis of coagulase gene polymorphisms. J Clin Microbiol 30, 1642-1645.

Gould, I. M., Girvan, E. K., Browning, R. A., MacKenzie, F. M. \& Edwards, G. F. S. (2009). Report of a hospital neonatal unit outbreak of community-associated methicillin-resistant Staphylococcus aureus. Epidemiol Infect 137, 1242-1248.

Groom, A. V., Wolsey, D. H., Naimi, T. S., Smith, K., Johnson, S., Boxrud, D., Moore, K. A. \& Cheek, J. E. (2001). Community-acquired methicillin-resistant Staphylococcus aureus in a rural American Indian community. JAMA 286, 1201-1205.

Lina, G., Piémont, Y., Godail-Gamot, F., Bes, M., Peter, M.-O., Gauduchon, V., Vandenesch, F. \& Etienne, J. (1999). Involvement of Panton-Valentine leukocidin-producing Staphylococcus aureus in primary skin infections and pneumonia. Clin Infect Dis 29, 11281132.

Mishaan, A. M. A., Mason, E. O., Jr, Martinez-Aguilar, G., Hammerman, W., Propst, J. J., Lupski, J. R., Stankiewicz, P., Kaplan, S. L. \& Hulten, K. (2005). Emergence of a predominant clone of community-acquired Staphylococcus aureus among children in Houston, Texas. Pediatr Infect Dis J 24, 201-206.

Naimi, T. S., LeDell, K. H., Como-Sabetti, K., Borchardt, S. M., Boxrud, D. J., Etienne, J., Johnson, S. K., Vandenesch, F., Fridkin, S. \& other authors (2003). Comparison of community- and health careassociated methicillin-resistant Staphylococcus aureus infection. JAMA 290, 2976-2984.

Schuenck, R. P., Nouér, S. A., Winter, C. de O., Cavalcante, F. S., Scotti, T. D., Ferreira, A. L. P., Giambiagi-de Marval, M. \& dos Santos, K. R. N. (2009). Polyclonal presence of non-multiresistant methicillin-resistant Staphylococcus aureus isolates carrying SCCmec IV in health care-associated infections in a hospital in Rio de Janeiro, Brazil. Diagn Microbiol Infect Dis 64, 434-441.

Smyth, D. S., Feil, E. J., Meaney, W. J., Hartigan, P. J., Tollersrud, T., Fitzgerald, J. R., Enright, M. C. \& Smyth, C. J. (2009). Molecular genetic typing reveals further insights into the diversity of animal-associated Staphylococcus aureus. J Med Microbiol 58, 13431353.

Song, X., Perencevich, E., Campos, J., Short, B. L. \& Singh, N. (2010). Clinical and economic impact of methicillin-resistant Staphylococcus aureus colonization or infection on neonates in intensive care units. Infect Control Hosp Epidemiol 31, 177-182.

Sung, J. M.-L., Lloyd, D. H. \& Lindsay, J. A. (2008). Staphylococcus aureus host specificity: comparative genomics of human versus animal isolates by multi-strain microarray. Microbiology 154, 19491959.

Tokajian, S. T., Khalil, P. A., Jabbour, D., Rizk, M., Farah, M. J., Hashwa, F. A. \& Araj, G. F. (2010). Molecular characterization of Staphylococcus aureus in Lebanon. Epidemiol Infect 138, 707712 . 
Udo, E. E. \& Sarkhoo, E. (2010). The dissemination of ST80-SCCmecIV community-associated methicillin resistant Staphylococcus aureus clone in Kuwait hospitals. Ann Clin Microbiol Antimicrob 9, 31.

Udo, E. E., Pearman, J. W. \& Grubb, W. B. (1993). Genetic analysis of community isolates of methicillin-resistant Staphylococcus aureus in Western Australia. J Hosp Infect 25, 97-108.

Udo, E. E., Farook, V. S., Mokadas, E. M., Jacob, L. E. \& Sanyal, S. C. (1999). Molecular fingerprinting of mupirocin-resistant methicillinresistant Staphylococcus aureus from a burn unit. Int J Infect Dis 3, 82-87.
Udo, E. E., O'Brien, F. G., Al-Sweih, N., Noronha, B., Matthew, B. \& Grubb, W. B. (2008). Genetic lineages of community-associated methicillin-resistant Staphylococcus aureus in Kuwait hospitals. $J$ Clin Microbiol 46, 3514-3516.

Zhang, K., McClure, J.-A., Elsayed, S., Louie, T. \& Conly, J. M. (2005). Novel multiplex PCR assay for characterization and concomitant subtyping of staphylococcal cassette chromosome mec types $\mathrm{I}$ to $\mathrm{V}$ in methicillin-resistant Staphylococcus aureus. J Clin Microbiol 43, 5026-5033. 